\title{
The Effect of Human Colostrum on Neutrophil Function
}

\author{
BENGT BJÖRKSTÉN, LEIF GOTHEFORS, AND RAGNAR SIDENVALL
}

Department of Pediatrics, University Hospital, Umea, Sweden

\section{Summary}

Strains of Escherichia coli were opsonized in human colostrum via heat stable opsonins and the classic complement pathway, but colostrum lacked capacity to opsonize $E$. coli via the alternative pathway. There was no bacteriostatic activity against serum sensitive $E$. coli strains, although specific antibodies against the strains were present. Neutrophils suspended in colostrum had normal chemotaxis and this was not altered by treating the colostrum with $\mathrm{HCl}$.

\section{Speculation}

Possibly the migration of neutrophils to the intestinal wall and lumen in response to cytotaxic factors may be enhanced by colostrum. Milk derived opsonins may enhance phagocytosis. Human breast milk may, thus, play a role in the defense against bacteria in the gut of the nursed infant and locally in the mammary gland by promoting neutrophil chemotaxis and phagocytosis.

Clinical studies have demonstrated that human breast milk may protect against infections in infants $(22,23,30,32)$. Reasons for this are not completely understood. Human breast milk, particularly colostrum, contains a number of substances with antimicrobial activity e.g., immunoglobulins, complement, lysozyme, and lactoperoxidase $(17,21)$. The physiochemical properties of breast milk, e.g., low buffering capacity and a low $\mathrm{pH}$, may also protect against invasion of pathogenic bacteria by promoting colonization of the infant's gut by bifidobacteria (18). Earlier studies of colostral cell function have mainly focused on lymphocytes and macrophages while little is known about neutrophil function in colostrum $(17,25)$.

Neutrophils play a critical role in defense against bacterial infections, particularly in the early stages of infection before a specific immune response against the invading microorganisms has evolved (10). In the gut, phagocytic cells in the lamina propria may engulf invading bacteria (14). Thus, neutrophils derived from the infant may play a role in the local defense against infection. Therefore, we decided to investigate human colostrum with regard to bacteriostatic activity and capacity to promote neutrophil chemotaxis, phagocytosis, and bacterial killing and report here the results of the studies.

\section{MATERIALS AND METHODS}

\section{COLOSTRUM}

Colostrum was obtained from healthy Swedish mothers during the first 2 days of lactation. The milk was centrifugated at 2000 $\times g$ for $15 \mathrm{~min}$ to remove cells and fat and was either used in the tests within $2 \mathrm{hr}$ after collection or frozen in vials and stored at $-80^{\circ} \mathrm{C}$. No samples were refrozen. The $\mathrm{pH}$ of the "milk serum" was measured with a $\mathrm{pH}$ meter 28 (Radiometer, Copenhagen) and found to be $7.3 \pm 0.24$ (SD).

\section{PREPARATION OF POOLED SERUM}

Sera from six healthy adults were mixed and frozen at $-80^{\circ} \mathrm{C}$ within $2 \mathrm{hr}$ of collection. The sera were tested for possible cytotoxic effects in cell tissue cultures as described elsewhere (6).

\section{PREPARATION OF LEUKOCYTE SUSPENSIONS}

Leukocyte-rich suspensions were obtained by dextran-sedimentation of venous blood drawn from a cubital vein and collected in heparinized glass tubes $(40 \mathrm{IU} / \mathrm{ml})$. For bactericidal tests, the leukocyte-rich supernatant fluid was washed twice in $0.022 \mathrm{M}$ phosphate buffer, pH 7.3 (PBS) with 1 IU heparin/ml added and then the cells were suspended in the same type of buffer solution to a concentration of $10^{7}$ polymorphonuclear cells (PMN) per ml. For chemotactic assays, the leukocytes were washed once in Hanks buffered saline solution containing $30 \mathrm{mM}$ HEPES ( $\mathrm{pH} 7.4$ ) solution and suspended to a concentration of $2-4 \times 10^{6}$ granulocytes per ml.

\section{PREPARATION OF BACTERIA}

The $E$. coli 0 serotypes used to test the bacteriostatic activity of colostrum were $02,018,022$, and 085 . These serotypes, except 085 , have a high prevalence in the fecal $E$. coli flora of healthy neonates (18). They were all sensitive to serum cidal activity.

Strains of $E$. coli which had the capacity to activate complement via the alternative pathway and strains lacking this capacity were used in the phagocytosis studies (8). The strains were clinical isolates: from feces of healthy infants and from the cerebrospinal fluid of neonates with meningitis. The Staphylococcus aureus strain used was the laboratory strain KS 755 . All the strains were serum resistant.

Overnight, broth cultures of the actual strains. were washed twice in PBS and diluted to a final concentration of about $1 \times 10^{5}$ colony forming units per $\mathrm{ml}$ when the bacteriostatic capacity of colostrum was tested and about $5 \times 10^{7}$ colony forming units in the phagocytosis assays.

\section{BACTERIOSTATIC ACTIVITY OF COLOSTRUM}

Amounts of $0.4 \mathrm{ml}$ colostrum, pooled serum, or PBS were mixed with $0.1 \mathrm{ml}$ of the bacterial suspension and $0.5 \mathrm{ml}$ PBS in plastic disposable tubes. The tubes were incubated in air at $37^{\circ}$ for $3 \mathrm{hr}$ on a tilting table (32 rotations per $\mathrm{min}$ ). Samples of $0.1 \mathrm{ml}$ were drawn at the different time intervals given in Figure 1. Viable bacterial counts of dilutions in distilled water of the samples were done in duplicate on blood-agar plates. Each of the 10 different strains was tested at least twice.

\section{CHEMOTACTIC ASSAYS}

The "leading front technique" as described by Wilkinson (31) was employed. Briefly, washed leukocytes suspended in serum, colostrum, or saline were placed in the upper part of a chemotactic chamber separated by a 3 micron Millipore filter (Millipore AB, Göteborg, Sweden). Saline, colostrum, or zymosan treated pooled serum diluted 1:20 in saline were placed in the lower compartment. 


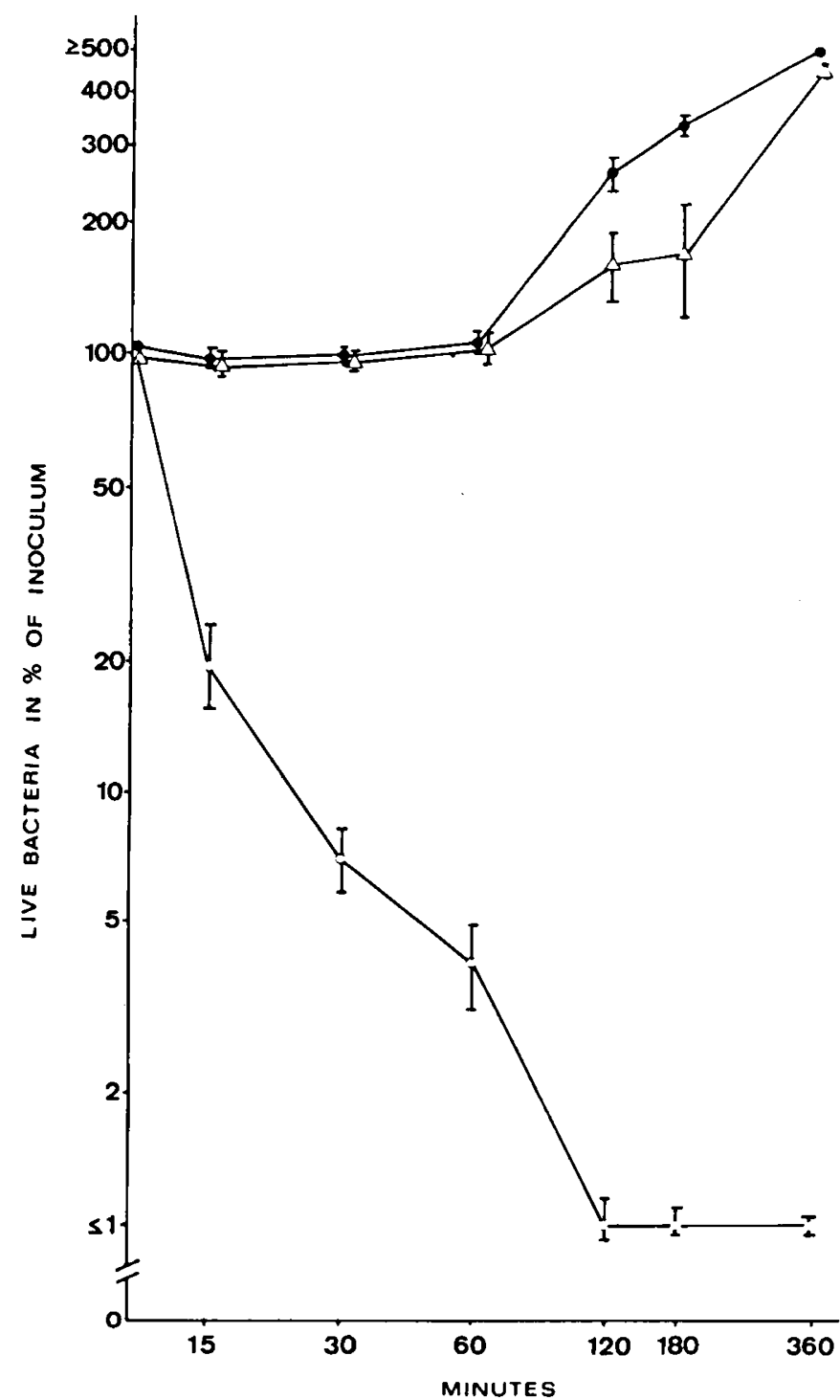

Fig. 1. Killing of E. coli in pooled colostrum (closed circles) pooled human serum (open circles) and in phosphate buffered saline PBS (open triangles). Mean and \pm SEM for 10 different strains.

To test whether acidified colostrum had more potent chemotactic agents than native colostrum, some samples of milk were treated with $\mathrm{HCl}(30 \mathrm{mEq} / \mathrm{liter})$ in proportion 1:10 for $2 \mathrm{hr}$ at $37^{\circ} \mathrm{C}$. The $\mathrm{pH}$ was restored to 7.3 by adding $0.1 \mathrm{~N} \mathrm{NaOH}$.

The chambers were incubated for $60 \mathrm{~min}$ at $37^{\circ} \mathrm{C}$ and the filters were then removed, stained with Harris' Haematoxylin, cleared with xylol, and mounted on glass slides. The distance, expressed in microns traveled by the leading front leukocytes, was measured using a microscope with a magnification of $400 \mathrm{X}$.

\section{PHAGOCYTOSIS ASSAYS}

A modification of the Maaløe method of phagocytosis, as described by Quie et al. (26), was used. Briefly $0.5 \mathrm{ml}$ of the PMN suspension was mixed with $0.4 \mathrm{ml}$ pooled serum, colostrum, or Hanks buffered saline solution. An amount of $0.1 \mathrm{ml}$ bacterial suspension was added. The test mixtures were incubated at $37^{\circ} \mathrm{C}$ on a tilting table and samples for determination of viable bacteria were drawn after $0-, 30$-, and $60-\mathrm{min}$ incubation.

\section{CHEMILUMINESCENCE}

Neutrophil chemiluminescence was measured in a liquid scintillation counter during phagocytosis of preopsonized zymosan particles as described elsewhere (7). Colostrum or pooled serum was used as opsonin source.

\section{QUANTITATION OF COLOSTRAL ANTIBODIES}

This was done by either of two methods: the enzyme-linked immunosorbent assay as described by Ahlstedt et al. (2) or by measuring hemagglutination-inhibiting antibodies (3). The somatic antigens of the $E$. coli strains were used in the assays. The amounts of specific antibodies in colostrum against the $E$. coli serotypes were expressed for enzyme-linked immunosorbent assay technique in percent of a reference serum and were found in levels comparable to those seen in other studies of human colostrum (18). The amount of hemagglutination-inhibiting antibodies were expressed as the reciprocal titer (Table 1).

\section{RESULTS}

As shown in Figure 1, there was no killing of $E$. coli in fresh human colostrum, whereas there was a rapid killing in pooled serum. Similar results were obtained for 10 different strains of $E$. coli including strains with capacity to activate the alternative complement pathway and strains lacking this capacity. The colostrum samples contained specific antibodies against all these $E$. coli strains.

Normal neutrophils suspended in undiluted pooled colostrum or serum had similar chemotactic responsiveness towards zymosanactivated serum (Fig. 2). When colostrum was diluted $1 / 5$ and $1 / 10$, chemotaxis was enhanced more than in undiluted colostrum. Further dilution diminished colostral enhancement of chemotaxis.

Table 1. Migration of neutrophils in modified Boyden chambers under various conditions

\begin{tabular}{lllc}
\hline \multicolumn{1}{c}{$\begin{array}{c}\text { Cells } \\
\text { suspended in }\end{array}$} & $\begin{array}{c}\text { Medium in } \\
\text { lower chamber }\end{array}$ & $n$ & $\begin{array}{c}\text { Distance in microns } \\
\text { travelled by leading } \\
\text { front leukocytes } \\
\text { (mean and range) }\end{array}$ \\
\hline $\mathrm{NaCl}$ & $\mathrm{NaCl}$ & 6 & $20(8-30)$ \\
$\mathrm{NaCl}$ & $\mathrm{Colostrum}$ & 4 & $26(10-42)$ \\
Colostrum & $\mathrm{NaCl}$ & 6 & $28(10-44)$ \\
Serum & $\mathrm{NaCl}$ & 6 & $65(38-86)$ \\
Serum & Colostrum & 4 & $58(40-85)$ \\
\hline
\end{tabular}

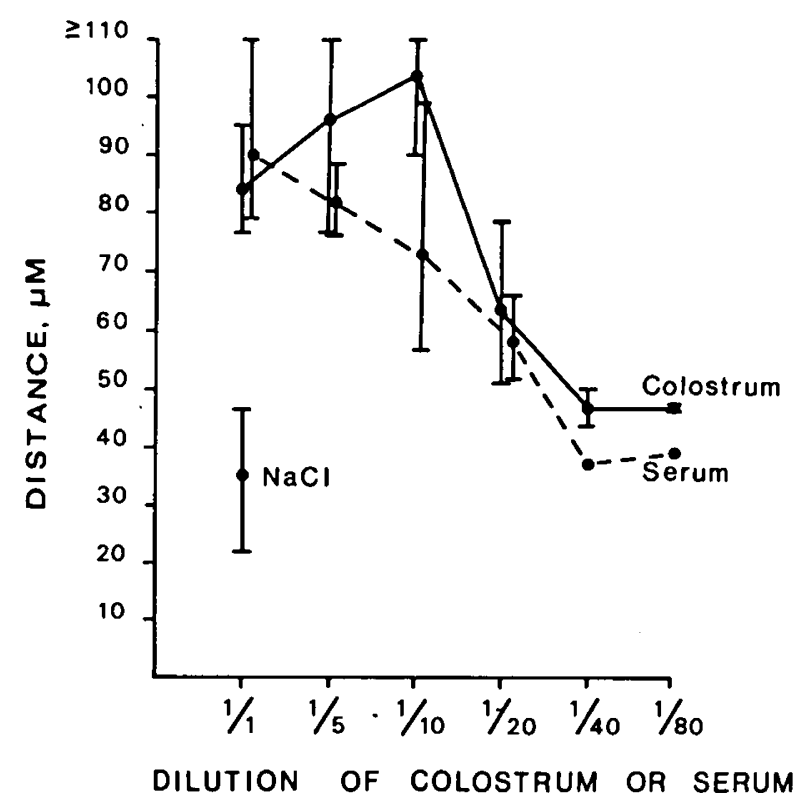

Fig. 2. Chemotaxis (mean and range) of neutrophils suspended in $\mathrm{NaCl}$ or various dilutions of pooled colostrum or serum. Zymosan-activated pooled human serum was used as cytotaxin. 


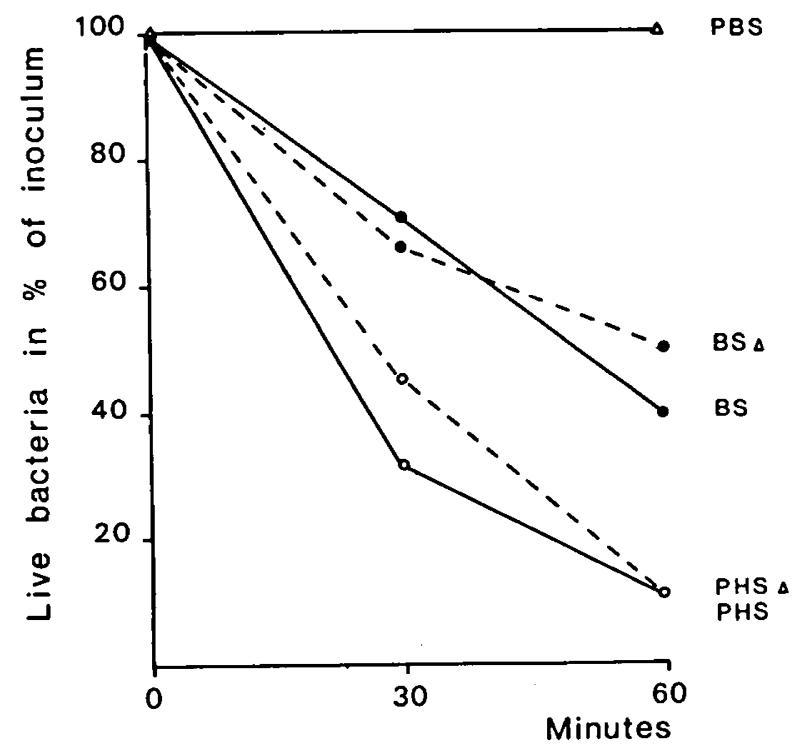

Fig. 3. Opsonization of $S$. aureus in fresh (lines) of heat-inactivated (dotted lines) pooled colostrum (BS), pooled serum (PHS) and in phosphate buffered saline (PBS).
The enhancement of neutrophil chemotaxis was abolished by inactivating colostrum or serum for $60 \mathrm{~min}$ at $56^{\circ} \mathrm{C}$. Treatment of colostrum with $\mathbf{H C l}$ for $2 \mathrm{hr}$ did not influence neutrophil chemotactic responsiveness. Colostrum was not cytotaxic, i.e., it did not attract neutrophils suspended in PBS or in pooled serum (Table 1). Random migration of neutrophils was not significantly enhanced by colostrum.

There was opsonic activity in pooled colostrum against $S$. aureus and four of the six serum resistant $E$. coli strains tested. As shown in Figures 3 and 4, the opsonic activity of colostrum against all strains was lower than that of serum. Addition of colostrum to control tubes in which bacteria were opsonized in serum did not influence phagocytosis, indicating that colostrum was not inhibitory to PMN phagocytosis and killing.

There were detectable antibodies against the four $E$. coli strains that were opsonized in colostrum (Table 2). The antibody titers against the two strains that were not opsonized in the pooled colostrum were low or not detectable. These two strains both have the capacity to activate complement via the alternative pathway and are, thus, opsonized in serum even in the absence of specific antibodies.

Heat-inactivation of pooled serum and colostrum did not inhibit $S$. aureus opsonization significantly whereas opsonization of the $E$. coli strains was inhibited.

Chemiluminescence of control neutrophils was not enhanced by zymosan preopsonized in colostrum (Fig. 5).
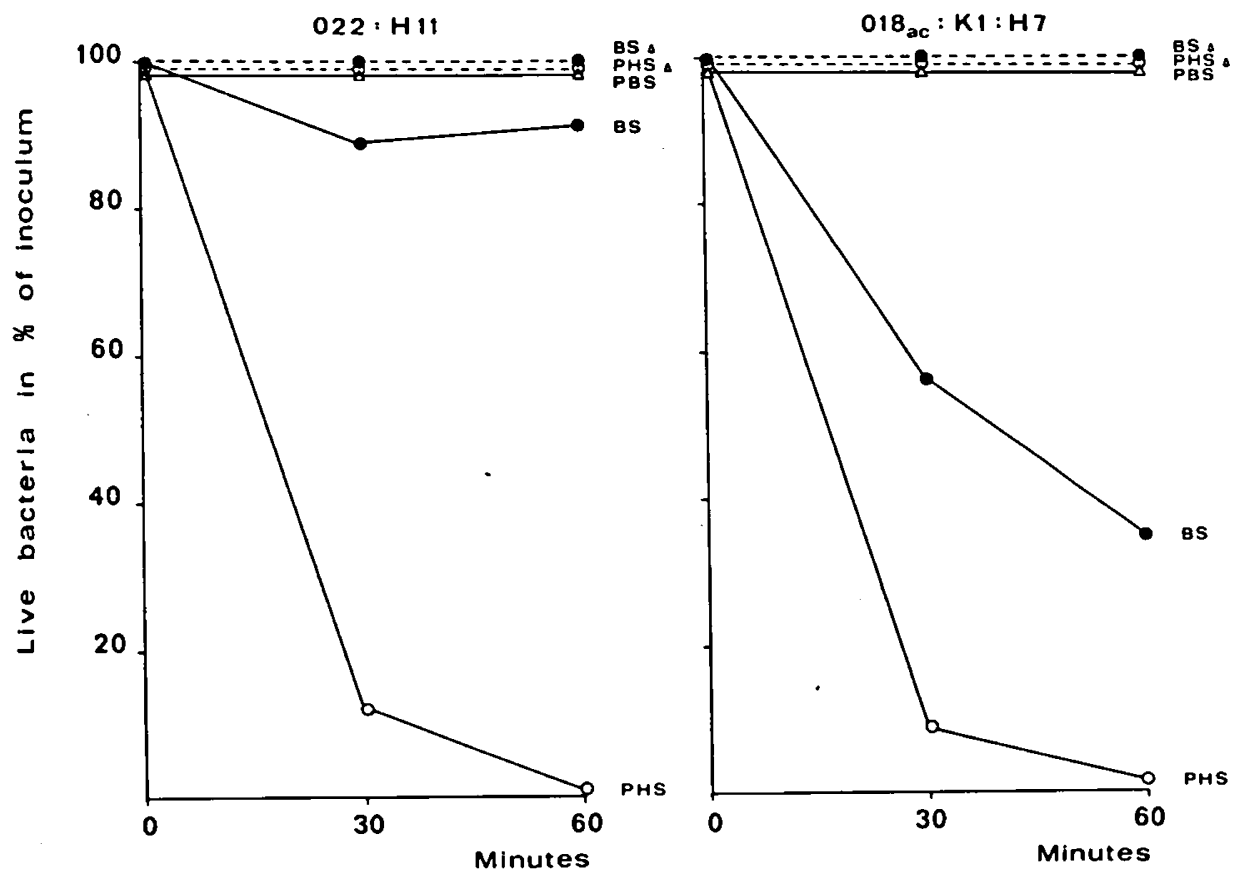

Fig. 4. Opsonization of $E$. coli $022: \mathrm{H} 11$ with the capacity to activate the alternative complement pathway and $E$. coli 018 ac:K1:H7 lacking the capacity. Full lines denote fresh and dotted lines heat-inactivated colostrum (BS), serum (PHS and PBS).

Table 2. Certain characteristics of six $E$. coli strains used to test opsonic and bacteriostatic activity in human colostrum

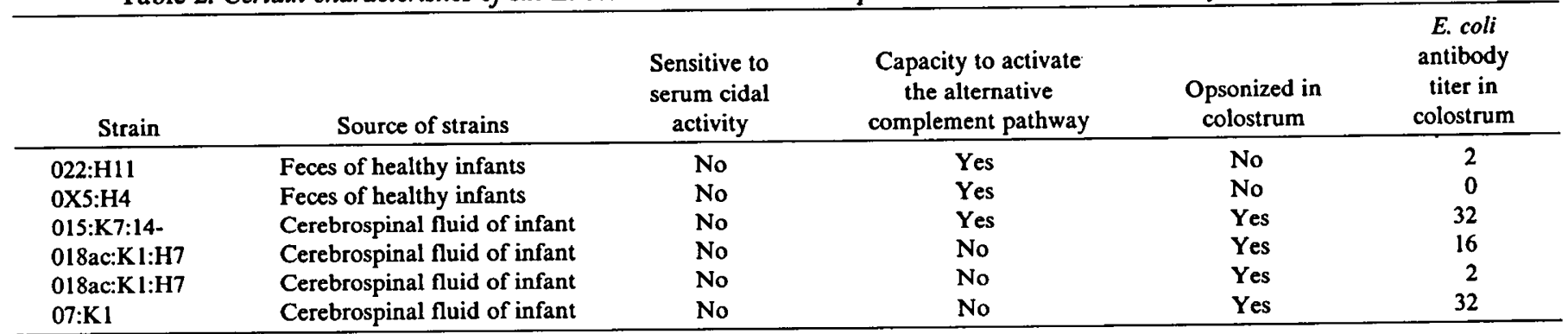




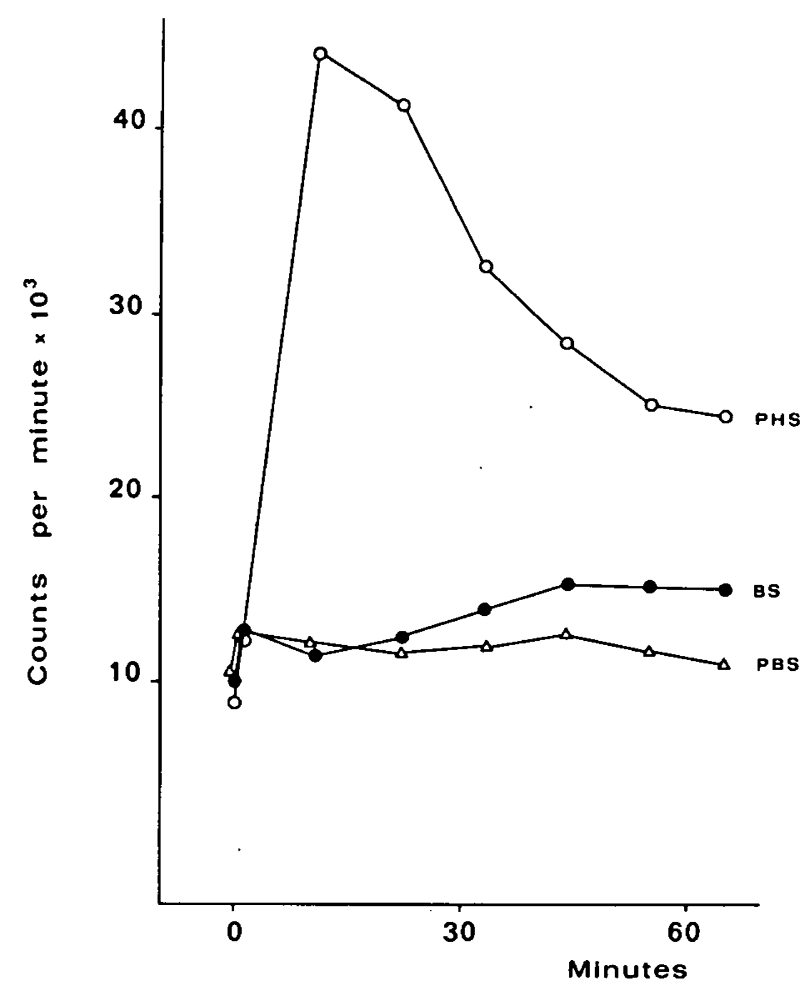

Fig. 5. Chemiluminescence in counts per minutes by control neutrophils during phagocytosis of zymosan particles opsonized in human serum (PHS), colostrum (BS), or phosphate buffered saline (PBS).

\section{DISCUSSION}

Several authors have demonstrated that breast-fed infants are less prone to bacterial infections than are bottle-fed. Most studies have not distinguished whether human milk is protective or simply a less frequent conveyor of pathogenic microorganisms (17). The clinical studies of Larguia et al. (22) and Mata et al. (23), however, strongly suggest that colostrum even in small amounts protects against enteric infections.

Studies of the possible role of breast milk are, however, complicated by the complex environment of the gut lumen and of the mammary gland where several defense mechanisms interact to prevent infection.

In this study, there was no bacteriostatic activity against serum sensitive strains of $E$. coli, although specific antibodies against all the strains were present in the colostrum samples. After the initial logphase, there was a logarithmic growth of the bacterial strain in colostrum and in buffer solution. Bacteriostatic effect of milk has, however, been shown by others and has been attributed to the combined action of unsaturated lactoferrin and specific antibody (13). It was initially shown for bovine colostrum after the milk pH had first been adjusted to 7.4. This adjustment implied the addition of bicarbonate in order to counteract the citrate normally present in these secretions. Citrate acts by mobilizing iron which saturates the lactoferrin and so invalidates its effects (20). Possibly the lack of bacteriostatic effect in our experiments, thus, may have been a result of nonoptimal experimental conditions. However, Dolby et al. (16) recently demonstrated fresh human milk to be bacteriostatic for some $E$. coli strains, even without addition of bicarbonate. Those experiments may indicate that human milk is bacteriostatic in vivo because there is rapid absorption of citrate from the gut and the presence of bicarbonate in the gut lumen would provide a proper environment for the combined effect of lactoferrin and antibody.

Because heat sterilization and, to a lesser degree, pasteurization, damage most of the antimicrobial factors in milk, there is increasing interest in the possibilities of using fresh milk for immature infants. Our data indicate that there is no bacterial growth in fresh unheated milk for the first 1-2 hr. Activation of one of the natural antimicrobial systems of milk (lactoperoxidase/thiocyanate/hydrogenperoxide) (19), resulting in "cold sterilization" has been proposed by Reiter et al. (27) as a possibly useful method of giving human milk with low bacterial counts. Presumably breast milk could be given continuously to tube-fed preterm babies provided that the syringe containing the milk is exchanged with regular intervals.

We found that colostrum stimulated neutrophil chemotactic responsiveness. This effect on chemotaxis was most obvious when the cells were suspended in a 1:10 dilution of colostrum (Fig. 2). Random migration was not increased by colostrum and our data presented in Table 1 and Figure 2 do not support the presence of nonspecific activators of neutrophil movement similar to those in serum.

Apparently, colostral enhancement of chemotaxis depended on heat labile factors because the effect was abolished when colostrum was heated. Treatment of colostrum with $\mathrm{HCl}, 30 \mathrm{mEq} / \mathrm{liter}$ for $2 \mathrm{hr}$ did not influence enhancement of chemotaxis. This concentration of $\mathrm{HCl}$ is similar to what is found in the stomach of infants (1). Possibly colostrum in vivo may enhance transport of leukocytes from the lamina propria to the lining of the epithelial cells or into the gut lumen.

The complement components C3 and C4 are present in colostrum in concentrations comparable to those in serum, but they fall to low levels within a few days $(18,24)$. However, even a concentration only $1-5 \%$ of that found in serum would allow opsonization by complement activation via the classic pathway (9). We found that $S$. aureus and certain $E$. coli strains were opsonized in colostrum. Two $E$. coli strains against which the pooled colostrum lacked or had low antibody activity were not opsonized. These two strains have the capacity to activate complement via the alternative pathway and are, thus, opsonized in serum independent of presence of antibodies (8). Apparently, there was no opsonization via the alternative pathway in colostrum.

The lack of capacity to activate the alternative pathway in colostrum was supported by the chemiluminescence assays. As shown in Figure 4, zymosan which is opsonized by activating complement via this pathway, was not opsonized in colostrum. Our results support those of Brock et al. (12) who found the bactericidal effect of bovine milk to depend entirely on the classical complement pathway. Also, in another study in which IgMfree $\operatorname{sIgA}$ in combination with antigen was used, no alternative pathway activation was shown (15).

Breast milk contains properdin and $\mathrm{C} 3$ proactivator in low concentrations (4). These levels may be too low to allow activation of complement via the alternative pathway. Other possible explanations for the lack of components of this pathway and the possibility that the low concentration of $\mathrm{C} 3$ in colostrum may only allow activation via the classic pathway.

Complement is inactivated by trypsin and chymotrypsin (12) and changed to inactive conversion products after incubation with gastric juice from small infants (18). Although the internal milieu of adult gut is said to be "anticomplementary", little is known about this in the neonatal period. The production of several complement factors in relation to the gastrointestinal tract (24) may suggest an effect of these factors in mucosal defense. Possibly the opsonins of colostrum may contribute to these effects. Also they may play a role in protecting against infection in the mammary gland of the mother and possibly, locally, in the proximal parts of airways and gastrointestinal tract of the infant (4).

There are phagocytic cells, e.g., macrophages, present in human milk. They are, however, loaded with lipid and it is not known whether this affects their bactericidal capacity or not (25). Casein loaded bovine milk PMNs (29) have a low killing activity. Thus, phagocytes present in human milk may play a very limited role in the defense against infection in the infant. However, experimental work indicates that immune-mediated emigration of neutrophils into the gut lumen may occur (15). Rowley (28) suggested that, in 
mice, Vibria cholerae are eliminated in presence of specific antibodies by phagocytes migrating from the peritoneum. Studies of resistence to enteric fever in mice suggested that a great portion of invading virulent salmonella organisms may be immediately inactivated by the normal host macrophages in the mucosa (11). These studies indicate that neutrophils emigrating from the gut wall may play a role in the local intestinal defense against invading microorganisms.

Among the numerous factors in human milk with possible antimicrobial effects, the antiadhesive properties of secretory IgA particularly are essential in the first line of defense. Some organisms might, however, break through this line of defense and then neutrophils may play a protective role. Possibly the migration of neutrophils to the intestinal wall and lumen in response to cytotaxic factors may be enhanced by colostrum present in the gut lumen. The cells may then exert phagocytosis enhanced by milk derived opsonins. Colostral effects on neutrophil function may, thus, possibly aid in the protection against invading bacteria in the gut.

\section{REFERENCES AND NOTES}

1. Agunod, M. Yamaguchi, N. Lopez, R., Luhby, A. L., and Glass, G. B. J.: Correlative study of hydrochloric acid, pepsin, and intrinsic factor secretion in newborns and infants. Amer. J. Digest Dis., 14: 400 (1969).

2. Ahlstedt, S., Carlsson, B., Hanson, L. A., and Goldblum, R. M.: Antibody production by human colostral cells. I. Immunoglobulin class, specificity, and quantity. Scand. J. Immunol., 4: 535 (1975).

3. Andersen, H. J.: Studies of urinary tract infections in infancy and childhood. IX. Determination of $E$. coli antibodies by a polyvalent antigen. Acta Paediatr. Scand., 56: 637 (1967).

4. Ballow, M., Fang, F., Good, R. A., and Day, N. K.: Developmental aspects of complement components in the newborn. The presence of complement components and C3 proactivator (proderdin factor B) in human colostrum. Clin. Exp. Immunol., 18: 257 (1974).

5. Bellamy, J. E., and Nielsen, N. O.: Immune-mediated emigration of neutrophils into the lumen of the small intestine. Infect. Immun., 9: 615 (1974).

6. Björkstén, B.: The NBT-test using venous and capillary blood. Scand. J. Haematol., 11: 270 (1973).

7. Björkstén, B., Bäck, O., Hägglöf, B., and Tärnvik, A.: Immune function in Down's syndrome. In: F. Güttler: Proceedings of the 15th annual meeting of the Society for the Study of Inborn Errors of Metabolism. (London, LTE press, 1978) (in press).

8. Björkstén, B., Bortolussi, R., Gothefors, L., and Quie, P. G.: Interaction of E. coli strains with human serum: lack of relationship to $\mathrm{Kl}$ antigen. J. Pediatr., 89 : 892 (1976).

9. Björkstén, B., Peterson, P. K., Verhoef, J., and Quie, P. G.: Limiting factors in bacterial phagocytosis by polymorphonuclear leukocytes. Acta Pathol. Microbiol. Scand., 35: 345 (1977).

10. Björkstén, B., and Quie, P. G.: Abnormalities of circulating phagocyte function. In: R. A. Thompson: Recent Advances in Clinical Immunology. p. 181 (Edinburgh, Churchill Livingstone, 1977).

11. Blanden, R. V., Mackaness, G. B., and Collins, F. M.: Mechanisms of acquired resistance in mouse typhoid. J. Exper. Med., 124: 585 (1966).
12. Brock, J. H., Piniero, A., and Ortega, F.: Bactericidal and haemolytic activity of complement in bovine colostrum and serum: effect of proteolytic enzymes and ethylene glycol tetraacetic acid (EGTA). Ann. Immunol., I26 C: 439 (1975).

13. Bullen, J. J., Rogers, H. J., and Leigh, L.: Iron-binding proteins in milk and resistance to Escherichia coli infection in infants. Brit. Med. J., 1: 69 (1972).

14. Collins, F. M., and Carter, P. B.: Cellular immunity in enteric disease. Amer. J. Clin. Nutr., 27: 1424 (1974).

15. Colten, H. R., and Bienenstock, J.: Lack of $\mathrm{C} 3$ activation through classical or alternate pathways by human secretory IgA anti-blood group A antibody. Adv. Exp. Med. Biol., 45: 305 (1974).

16. Dolby, J. M., Stephens, S., and Honour, P.: Bacteriostasis of $E$. coli by milk. II. Effect of bicarbonate and transferrin on the activity of infant faeces. J. Hygeine, 78: 235 (1977).

17. Goldman, S. A., and Smith, C. W.: Host resistance factors in human milk. J. Pediatr., 82: 1082 (1973).

18. Gothefors, L.: Studies of antimicrobial factors in human milk and bacterial colonization of the newborn. Umea Univ. Med. Diss. N.S., 7: 000 (1975).

19. Gothefors, L., and Marklund, S.: Lactoperoxidase activity in human milk and saliva of the newborn infant. Infect. Immun., 11: 1210 (1975).

20. Griffiths, E., and Humphrey, J.: Bacteriostatic effect of human milk and bovine colostrum on $E$. coli: importance of bicarbonate. Infect. Immun., 15: 396 (1977).

21. Hanson, L. $\AA$., and Winberg, J.: Breast milk and defence against infection in the newborn. Arch. Dis. Childhood, 47: 845 (1972).

22. Larguia, A. M., Urman, J., Ceriani, J. M., O'Donnell, A., Stoliar, O., Martinez, J. C., Buscaglia, J. C., Weils, S., Quiroga, A., and Irazu, M.: Immunidad local en el recień nacido. Primera experiencia con la administracion de calostro humano a recień nacidos preteŕmino. Arch. Argent Pediatr., 72: 109 (1974).

23. Mata, L. J., Kronmal, R. A., Garcia, B., Butler, W., Urrutia, J. J., and Murrillo.: Breast-feeding, weaning and the diarrhoeal syndrome in a Guatemalan Indian Village. Ciba Found. Symp., 42: 311 (1976).

24. McClelland, D. B. L.: Humoral defense factors of the gastrointestinal tract. Thesis, University of Leiden. (1977).

25. Pitt, J.: Breast milk leukocytes, Pediatrics, 58: 769 (1976).

26. Quie, P. G., White, J. G., Holmes, B., and Good, R. A.: In vitro bactericidal capacity of human polymorphonuclear leukocytes. Diminished activity in chronic granulomatous disease. J. Clin. Invest., 46: 668 (1967).

27. Reiter, B., Marshall, V. M. E., Björck, L., and Rosén, C.-G.: Nonspecific bactericidal activity of the lactoperoxidase-thiocyanate-hydrogen peroxide system of milk against Escherichia coli and some gram-negative pathogens. Infect. Immun., 13: 800 (1976)

28. Rowley, D.: Specific immune antibacterial mechanisms in the intestines of mice. Amer. J. Clin. Nutr., 27: 1417 (1975).

29. Russel, M. W., Booker, B. E., and Reiter, B.: Inhibition of the bactericidal activity of bovine polymorphonuclear leucocytes and related systems by casein. Res. Vet. Sci., 20: 30 (1976).

30. Svirsky-Gross, S.: Pathogenic strains of coli (0:111) among prematures and the use of human milk in controlling the outbreak of diarrhea. Ann. Paediatr., 190: 109 (1958)

31. Wilkinson, P. C.: Chemotaxis and Inflammation. p. 168-172 (Churchill Livingstone, Edinburgh, 1974).

32. Winberg, J., and Wessner, G.: Does breast milk protect against septicaemia in the newborn? Lancet, $1: 1091$ (1971).

33. This research was supported by grants from The Swedish Medical Research Council 04990 (The Wenner-Gren foundation, Arla (B. B.) and the J. C. Kempe foundation (L. G.)

34. Requests for reprints should be addressed to: Bengt Björkstén, M. D., Department of Pediatrics, University Hospital, 90185 Umeả, Sweden.

35. Received for publication March $14,1978$.

36. Accepted for publication June 29, 1978. 